\title{
Early surgical intervention versus conventional treatment in posterior epistaxis: a systematic review
}

\begin{abstract}
Background: Traditionally the posterior epistaxis is managed with nasal packing and prolonged hospital stay. However, the patient may undergo a cycle of nasal packing, repacking and eventual surgical intervention. This protocol could subject the patient to significant morbidity and may not be the cost effective strategy either. On the other hand, endoscopic sphenopalatine artery ligation (ESPAL) is increasingly employed and it has got an established role in the posterior epistaxis management. The proponents claim minimal morbidity associated with ESPAL, and regard it as an efficient, safe and cost effective treatment option compared to the traditional approach.
\end{abstract}

Aim: To compare the safety, efficacy and cost effectiveness of early surgical intervention with traditional treatment (packing with or without subsequent surgical intervention) in the management of posterior epistaxis.

Methods: Potentially eligible articles were identified from the following electronic databases: MEDLINE, EMBASE, The Cochrane Library including the Cochrane Central Register of Controlled Trials, Database of Abstracts and Reviews (DARE), and Google scholar. They were included if they fulfilled pre specified criteria. Data were extracted from the eligible studies according to a protocol developed for the purpose this study.

Results: Two RCTs and four retrospective reviews were included. Among the included studies, both RCTs were prospective trials. Both studies have reported reduced re-bleed rates with early surgical intervention compared to the traditional management. But these differences were not statistically significant. However, there was a statistically significant reduction in cost and the total hospital stay with early surgical intervention in both RCTs. The findings from RCTs were supported by all retrospective reviews.

Conclusion: Despite limited evidence, this systematic review favours early surgical intervention as opposed to traditional treatment with nasal packing. The duration of hospital stay and cost involved influence the choice of surgical intervention. However, further well designed multicentre randomised controlled clinical trials are required for a more definitive conclusion.

Keywords: Epistaxis; Posterior; Nasal packing; Foleys catheter; Surgery; Early intervention; Artery ligation; Endoscopy; Cost; Hospital stay duration; Anterior rhinoscopy; Bleeding; Septum; Cannula
Volume 3 Issue 5 - 2015

\author{
Mahalingappa Y,' Shakeel M, ${ }^{2}$ Vallamkondu V, ${ }^{2}$ \\ Karagama $Y^{3}$ \\ 'Department of ENT Surgery, Poole Hospital, UK \\ ${ }^{2}$ Department of Otolaryngology-Head and Neck surgery, \\ Aberdeen Royal Infirmary \\ ${ }^{3}$ Department of ENT Surgery, Tameside Hospital, UK
}

Correspondence: Yogesh Bevoor Mahalingappa, Department of ENT Surgery, Long fleet Rd, Poole, Dorset BHI5 2JB, Poole Hospital, Poole, UK, Email yogesh.mahalingappa@poole.nhs.uk

Received: November 08, 2015 | Published: December 08, 2015

\section{Introduction}

Epistaxis is derived from Greek 'to bleed from nose'. Epistaxis is one of the common presenting problem to Accident and Emergency departments. The bleeding can occur in different places inside the nose commonest being from the Little's area; cluster of blood vessels around anterior part of septum -the anterior epistaxis. The posterior epistaxis is defined when the bleeding point cannot be visualized with anterior rhinoscopy. ${ }^{1}$ Also those patients in whom an anterior bleeding point could not be found were by definition suffering from posterior epistaxis. In one study the authors located the bleeding site of posterior epistaxis on the posterior part of the lateral wall of nose in $80 \%$ of cases and in $20 \%$ it was found on the septum. ${ }^{2}$ Management of patients with posterior epistaxis involves failed conservative therapy of packing and repacking and then surgical treatment. Ancient Egyptians used ashes of papyrus mixed with vinegar to treat nosebleed. Powder made from mummies (mummiavera) was also used at the end of 17 th century. ${ }^{3}$ Hippocrates used sheep's wool on pugilistic noses in ancient Greece ${ }^{4}$ and also ancient Greeks and Romans practiced bloodletting for treatment of epistaxis. The traditional method of nasal packing for posterior epistaxis is cumbersome and causes pain and discomfort to patient. Pringle et al., 5 recommended use of Merocel nasal tampon for treatment of epistaxis. A Foley's catheter use to stop posterior bleed was described by Holland in 2001. ${ }^{6}$ However; there is a risk of respiratory complications and patients may develop sleep apnoea after placement of posterior nasal packing.?

Surgical management of uncontrolled epistaxis have evolved over years; in 1706; it was first suggested to apply cautery directly to the vessel; using a 'cannula' to protect the alar rim from the heat; but only if 'the patient's life seems to be in danger'. Abernethy in 1795 was the first to attempt to ligate the common carotid artery and the procedure was successfully applied to control haemorrhage by Flemming in $1803 .{ }^{8}$ Seiffert in 1928 made the procedure more specific by ligating the maxillary artery via a transantral approach. ${ }^{9}$ The failure rate following transantral ligation is around $0.5-15 \%$; according to Winstead; and failure happens due to the reconstitution of flow through collaterals ${ }^{10,11}$ Sphenopalatine artery is the most terminal artery supplying the nasal cavity; hence ligating it offers not only immediate control of epistaxis but also minimises the potential for the development of collateral vessels thereby avoiding failure or recurrence. ${ }^{12}$ The Systematic review by Feus ${ }^{13}$ was favourable towards ligation of sphenopalatine artery with better results for surgical treatment of posterior epistaxis. 
Budrovich and Saetti were among first to report endoscopic ligation of the sphenopalatine artery. ${ }^{14}$

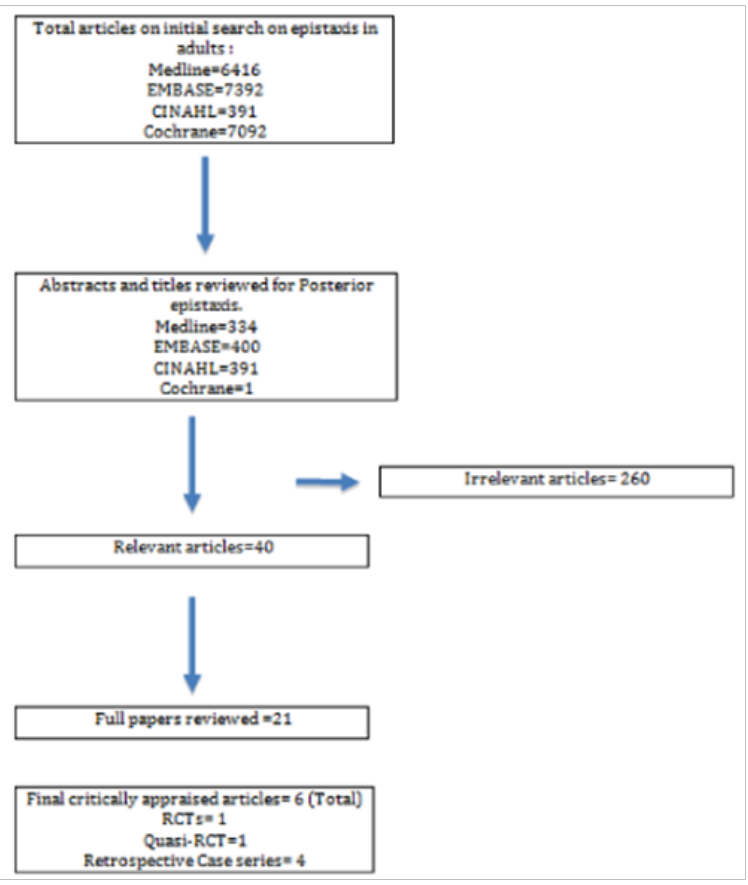

Figure I Literature search diagram.

\section{Aims of review}

To compare re-bleed rates in early surgical management with conventional (initial packing) treatment for posterior epistaxis. Whether early surgical intervention should be carried out without a conservative trial of tamponade and balloon technique. To compare the outcomes of length of hospital stay and cost incurred in early surgical management and conservative packing.

\section{Methods}

A comprehensive literature search was conducted using MEDLINE; EMBASE; CINAHL; The Cochrane Library including the Cochrane Central Register of Controlled Trials; and Google scholar database. The key words used were Posterior epistaxis; nose bleed; haemorrhage; Rhinorrhagia; nose packs; conservative treatment; surgery with the connecting verbs 'compare' and 'versus' (and their synonyms). Only English language literature was included but there was no restriction as to the design or date of publications. The date of final search was 1st of August 2011 with repeat search adding no articles in August 2014. The inclusion and exclusion criteria are shown in Table 1.

The titles and abstracts were screened independently by two researchers (YBM and MS) to identify potentially relevant articles. The full text articles were then obtained. The bibliography was also searched for other potentially relevant articles. All articles that met the inclusion criteria were reviewed for data extraction and quality assessment. Data extracted from each article included patient demographics; study design; type of surgical intervention performed; length of follow-up and outcomes measured. Literature was appraised using the critical appraisal tools and evidence was based on the levels of evidence as defined by the Oxford Centre of Evidence Based Medicine. ${ }^{15-17}$ The main review outcome was the recurrence of bleeding (re-bleed rates) with the primary initial intervention of posterior epistaxis. The secondary outcomes were the length of hospital stay; cost and complications related to the procedure.

\section{Results}

The literature search results are shown in Figure 1. A total of 7392 articles were obtained from the initial literature search. After reviewing the citations and abstracts; 40 were deemed to be potentially relevant. A further 19 articles were excluded as these studies did not meet the inclusion criteria. All excluded articles were retrospective studies. The full texts of the remaining 21 papers were reviewed. 15 articles were found to be duplicate and were therefore removed. A total of 6 studies were available for final review and analysis; of these 1 was prospective randomized controlled trial (RTC); 1 quasi randomized prospective Trial; and 4 were retrospective studies.

In the reviewed randomised controlled trials McGarry ${ }^{18}$ and Moshaver et al. showed similar results of lower re-bleeding in early surgical group compared to conservative group. The study samples in both trials were low and it is not mentioned in either of the studies whether or not a power calculation was performed before the study. Moshaver et al. ${ }^{19}$ study was done on 19 patients with posterior epistaxis randomized into two groups. Whereas; in Mcgarry study a total of 25 patients were included in the study where the surgical intervention was endoscopic electro-cautery. In both RCTs there is no statistical evidence to say that the early surgical intervention has lesser re-bleed rates than the conventional packing. The Moshaver et al., ${ }^{19}$ study being a prospective randomised controlled trial falls into a level 1 evidence category. Patients did have an initial Merocel pack before being randomised; this could be a first step before they were randomised for initial treatment. The power calculation was not performed and this could have impacted on the re-bleed rate outcomes. Authors have noted that there was no statistical significance $(\mathrm{p}=0.141)$ in primary outcome that is the re-bleed rates in the two arms. This is not clear what test was used to compare the statistical significance as $50 \%$ of the conservative group had re-bleed compared to $11 \%$ in the surgical group. The Mc Garry study was a pilot study and a quasi randomized study; with randomization done based on days author was available to do surgical intervention. This may have selection bias. However the author mentions that the chosen patients in both groups were relatively well matched for age and sex. The surgical group in their study had lower re-bleed rates compared to packing group and it is not mentioned whether it was statistically significant (Tables $2 \& 3$ ).

With regards to secondary outcomes such as the mean duration of in-patient stay the early surgical group in both RCT had shorter period of hospital stay compared to packing group which was statistically significant (Moshaver; $\mathrm{p}=0.001$ and McGarry; $\mathrm{p}<0.05$ ). The retrospective case studies support the RCTs. The study conducted by Hernandez et al., ${ }^{20}$ the overall success rate for the first surgical intervention on patients with posterior epistaxis was $87 \%$ (Here 15 patients included- primary surgical intervention in 5 patients and 10 patients who had subsequent surgical intervention following failed conservative treatment). Whereas the success rate to stop bleeding was $45 \%$ in non- surgical (packing) treatment group. This difference of success rates between surgical group and nonsurgical group (packing) was statistically significant (Chi squared test $(\mathrm{p}=0.0001)$ ). One important results of this study was that the severity of posterior epistaxis was greater and showed higher morbidity than patients with anterior epistaxis leading to longer hospital stay $(\mathrm{p}=0.001)$ and require greater number of blood transfusion. Based on these findings the authors recommend the use of initial surgical treatment for posterior epistaxis. Moreover; the retrospective case series study 
by Klotz et al., ${ }^{21}$ showed the Group who had anterior and posterior packing $(\mathrm{n}=126)$ had $62 \%$ success rate compared to $90 \%$ success rate in surgical group. Also 13 patients $(6 \%)$ received surgical treatment as the primary option; and authors have not commented on success rate individually for this group but have shown this group had lesser hospital stay and was cost effective. In patients who were successfully treated with packing; the costs incurred for packing of posterior epistaxis was $\$ 5136$ per patient. Patients who received packing as first treatment that subsequently failed needing surgical intervention had treatment cost of $\$ 9117$ per patient. Authors also highlight that a small portion of patients $(6 \%)$ underwent primary surgical treatment for posterior epistaxis in their review and had lower cost (\$3851/patient) compared with other groups. Average hospitalization time for medical treatment $(5.29 \mathrm{~d})$ being significantly longer than hospitalization when compared with primary surgical intervention $(2.1 \mathrm{~d})(\mathrm{p}<0.01)$.

Table I Inclusion and exclusion criteria

Inclusion criteria

\section{I-Type of study:}

RCT, Quasi RCT Studies which had the outcomes criteria as a part of their study.

Retrospective case series were included for narrative synthesis purpose only

\section{2-Type of intervention:}

\section{Surgical interventions:}

Early surgical treatment is defined as surgical management of posterior epistaxis as a primary/ initial procedure or within 24 hours of admission to hospital.

This included the ligation or cautery of sphenopalatine artery, with and without concomitant ligation of the anterior ethmoidal artery of one side or both sides.

Conventional/Conservative management:

The packing of the nose (pack and wait) as initial management for posterior epistaxis. This included use of anterior packs and balloon posterior packs (anterior packs- merocel, rapid rhino,Vaseline gauze; Posterior packs-Balloon nasal packs and Foley's catheter.)

3- Participants

This review included all adults (that is more than 18 years of age) with posterior epistaxis. The both males and females from all ethnical backgrounds were included

\section{Exclusion criteria}

I. Patients with anterior epistaxis and children were excluded from the review.

Table 2 Results of McGarry study

\begin{tabular}{llllll} 
Intervention & Number & Re-bleeds & Hospital stay & Follow up at I month & Complications \\
\hline Packing & 13 & 3 & $4.5(2$ to 7$)$ & $77 \%$ & $\begin{array}{l}\text { I Myocardial infarction, } \\
\text { I septal perforation }\end{array}$ \\
Early Surgical & 12 & 1 & $2.7(1$ to 6$)$ & $92 \%$ & 0
\end{tabular}

Table 3 Results of study Moshaver et al ${ }^{19}$

\begin{tabular}{llllll}
\hline Intervention & Number of patients & Failure rate & Length & Cost & Follow up \\
\hline & & & Of stay (Mean) & Per patient & $\begin{array}{l}\text { (range 3 to I4 months using Telephone } \\
\text { questionnaire) }\end{array}$ \\
\hline Conservative & 10 & $50 \%$ & 4.7 & $\$ 12,213$ & $70 \%$ \\
\hline (Packing) & & & & & \\
\hline Early surgical & 9 & $11 \%$ & 1.6 & $\$ 5,133$ & $67 \%$ \\
\hline
\end{tabular}

Table 4 Outcomes of reviewed studies

\begin{tabular}{|c|c|c|c|c|c|c|c|c|}
\hline S.No & Authors & $\begin{array}{l}\text { No. of } \\
\text { Patients }\end{array}$ & Study Type & $\begin{array}{l}\text { Failure Rates (Re- } \\
\text { Bleed) }\end{array}$ & $\begin{array}{l}\text { Length } \\
\text { of Stay } \\
\text { (Mean } \\
\text { Days }\end{array}$ & $\begin{array}{l}\text { Cost } \\
\text { (Per } \\
\text { Patient) }\end{array}$ & Complication & $\begin{array}{l}\text { Follow } \\
\text { Up }\end{array}$ \\
\hline \multirow[t]{2}{*}{ I } & MCGarry & 19 & Quasi-RCT & $\begin{array}{l}\text { Packing }(n=3 / 13)= \\
23 \%\end{array}$ & 4.5 & & $\begin{array}{l}\text { I5\%(I Myocardial } \\
\text { infarction, I septal } \\
\text { perforation) }\end{array}$ & $\begin{array}{l}77 \% \text { at I } \\
\text { month }\end{array}$ \\
\hline & & & & $\begin{array}{l}\text { Early Surgical } \\
(n=1 / 12)=8 \%\end{array}$ & 2.7 & & 0 & $\begin{array}{l}92 \% \text { at I } \\
\text { month }\end{array}$ \\
\hline \multirow[t]{2}{*}{2} & $\begin{array}{l}\text { Moshaver } \\
\text { et al. [19] }\end{array}$ & 25 & $\mathrm{RCT}$ & $\begin{array}{l}\text { Packing } \\
(n=5 / 10)=50 \%\end{array}$ & 4.7 & $12,213 \$$ & & $\begin{array}{l}\text { 70\%(Range from } \\
\text { 3to I4 months) }\end{array}$ \\
\hline & & & & $\begin{array}{l}\text { Early Surgical } \\
(n=1 / 9)=11 \%\end{array}$ & 1.6 & $5,133 \$$ & & $\begin{array}{l}67 \% \text { (Range from } \\
\text { 3to } 14 \text { months) }\end{array}$ \\
\hline 3 & \multicolumn{2}{|c|}{ Hernandez et al. [20] } & $\begin{array}{l}\text { Retrospective } \\
\text { case series }\end{array}$ & $\begin{array}{l}\text { Packing } \\
(n=16 / 30)=53 \%\end{array}$ & 8.17 & & \multicolumn{2}{|c|}{$\begin{array}{l}10 \%(3 \text { nasal alae and or columellar } \\
\text { necrosis) }\end{array}$} \\
\hline
\end{tabular}


Table Continued...

\begin{tabular}{|c|c|c|c|c|c|c|c|}
\hline S.No & Authors & $\begin{array}{l}\text { No. of } \\
\text { Patients }\end{array}$ & Study Type & $\begin{array}{l}\text { Failure Rates (Re- } \\
\text { Bleed) }\end{array}$ & $\begin{array}{l}\text { Length } \\
\text { of Stay } \\
\text { (Mean } \\
\text { Days }\end{array}$ & $\begin{array}{l}\text { Cost } \\
\text { (Per } \\
\text { Patient) }\end{array}$ & Complication \\
\hline & & & & $\begin{array}{l}\text { Early Surgical } \\
(n=0)=0 \%\end{array}$ & 5.2 & & 0 \\
\hline \multirow[t]{3}{*}{4} & Klotz et al. $[21]$ & & $\begin{array}{l}\text { Retrospective } \\
\text { case series }\end{array}$ & $\begin{array}{l}\text { Packing }(n=77 / 203)= \\
38 \%\end{array}$ & 5.29 & $5,136 \$$ & $2 \%(3$ alar necrosis, I angina) \\
\hline & & & & $\begin{array}{l}\text { Surgical intervention } \\
10 \%\end{array}$ & $6 / 61)=$ & $9,117 \$$ & 0 \\
\hline & & & & $\begin{array}{l}\text { Early surgical } \\
(n=13)-\end{array}$ & 2.1 & $3,851 \$$ & - \\
\hline \multirow[t]{3}{*}{5} & Schaitkin & & $\begin{array}{l}\text { Retrospective } \\
\text { case series }\end{array}$ & $\begin{array}{l}\text { Packing }(n=31)= \\
52 \%(\text { early }), 3 \%(\text { late })\end{array}$ & 5.8 & $2,744 \$$ & $\begin{array}{l}20 \% \text { (Intranasal synechia, periorbital } \\
\text { cellulitis, Angina) }\end{array}$ \\
\hline & et al. [22] & & & & & & \\
\hline & & & & $\begin{array}{l}\text { Surgical }(n=17)= \\
12 \%(\text { early })\end{array}$ & 7.2 & $4795 \$$ & $\begin{array}{l}47 \% \text { (Myocardial infarction, Angina, intranasal } \\
\text { synechiae) oroantral fistula) infra orbital nerve } \\
\text { dysfunction, mucosal slough ,septal perforation) }\end{array}$ \\
\hline \multirow[t]{2}{*}{6} & Ha et al. [23] & & Retrospective & & 1.55 & & $\begin{array}{l}\text { I2\%(IDysrhytmia I Pack } \\
\text { dislodgement, IMI) }\end{array}$ \\
\hline & & & & $\begin{array}{l}\text { Early surgical } \\
(n=0 / 8)=0 \%\end{array}$ & 0.84 & & $0 \%$ \\
\hline
\end{tabular}

Although the comparison was not mainly for posterior epistaxis the retrospective study by $\mathrm{Ha}$ et al., ${ }^{22}$ shows the success rate (no re-bleeds) with early management of epistaxis patients with Nasoendoscopic cautery (NC) was $100 \%$ compared to $68 \%$ in conventional treatment (CT) group. Also NC group had had no complications while CT group had 2 patients with dysrhythmia; 1 required transfusion for anemia; 1 myocardial infarction; 1 had pack dislodgement. Difference between the groups in re-bleed rates along with other complications was statistically significant when compared between groups $(\mathrm{P}=0.005)$. With regards to average length of stay NC group had lower geometric mean of 0.84 days when compared to the $\mathrm{CT}$ group with an average of 1.55 days $(\mathrm{P}=0.049)$.

The contrasting results were found only in the earlier study done by Schaitkin et al., ${ }^{23}$ In their case series surgery was expensive and led to longer hospital stay and complications. The study was a retrospective review of 32 patients with epistaxis and found that the patient who had packing and then surgery had $47 \%$ complication rate compared to $22 \%$ in medical group. The surgical group had longer hospital stay of mean 7.2days compared to 5.8days in medical group. Moreover the Authors in their study had recommended 72 hours of initial packing with wait and watch policy; reserving surgery for patients who rebleed and have complications. However; there are some issues in their study; which led to these conclusions. During the time period when the study was conducted the maxillary artery ligation was main surgical treatment and had many complications. Also the study institution was a tertiary referral centre and received patients from other hospitals who already had failed 48 hours of packing for epistaxis. The authors in their conclusion of the study have also acknowledged that early surgery with ligation techniques would have reduced hospital stay and costs.

Our review has showed that Patient satisfaction was better in early surgical group. In the questionnaire study by Moshaver et al., ${ }^{19}$ patients who had had nasal packing felt the experience as painful and unpleasant; whereas in surgical group all patients were very satisfied with their treatment and would recommend this procedure to others. This is supported by clinical opinion by Mc Garry that patients who had initial intervention of endoscopy and local anaesthetic cautery well tolerated the procedure whereas the packing group suffered from discomfort.

\section{Discussion}

The epistaxis is a common presentation in ENT departments and there is variability in the clinical practice as to the best management option with regards to posterior epistaxis. Although numbers with re-bleed rates were less in early surgical intervention compared to initial packing group the differences in re-bleed rates had no statistical significance in both the prospective randomized studies. However; the studies show that early surgical intervention has better outcome with regards to hospital stay; cost and complication rates. There is statistical significance in both RCTs for shorter duration of hospital stay in initial surgical intervention group compared to initial Packing group. Also; patients' satisfaction was better with early surgical intervention than conventional packing.

Of 4 retrospective series study; $3^{20-22}$ favoured the early surgical intervention where as older retrospective case series by Schaitkin et al., ${ }^{23}$ showed that surgery was associated with more complications. In the included studies for this systematic review; failure rates (rebleed after primary intervention for posterior epistaxis) of packing were $23 \%$ to $53 \%$ and for early surgical intervention were $0 \%$ to $11 \%$. Average Length of hospital stay was 0.84 to 5.2 days for early surgical treatment and 1.55 to 8.17 days for packing group. Cost for early surgical treatment ranged from $3,851 \$$ to $5,133 \$$; whereas cost for packing (not including secondary surgery) ranged from $2,744 \$$ to $5,136 \$$. Complication rate (Excluding re-bleed and transfusion) in packing ranged from $2 \%$ to $20 \%$ and for early surgical treatment patient was $0 \%$. Systematic review by Feusi et al., ${ }^{13}$ looked at the optimal surgical management of the posterior epistaxis. They concluded that the ligation of the sphenopalatine artery is a favourable 
surgical treatment for posterior epistaxis. However; Feusi's review involved surgical procedure for patients with failed conservative treatment (after temponade or balloon packing) and mainly looked at retrospective case series. The authors also mentioned the need for further research to compare the early surgical treatment with packing for treatment of epistaxis. Also review by Kumar et al., ${ }^{24}$ looked into surgical management of posterior epistaxis and recommended endoscopic sphenopalatine artery ligation or cautery for management of posterior epistaxis. Our systematic review compares early surgical treatment with conventional nasal packing for variable duration in posterior epistaxis (Table 4 ).

\section{Conclusion}

This systematic review of the available literature favours early surgical intervention for posterior epistaxis as the duration of hospital stay and cost can be reduced by using this approach. There are however various nasal packing options available to stop the posterior epistaxis. The clinical practice should be based at the local expertise and resources availability. This review can guide the otolaryngologist in devising a plan for managing the posterior epistaxis. However further well designed multicentre randomised controlled clinical trials are required for a more definitive conclusion.

\section{Acknowledgments}

None.

\section{Conflicts of interest}

Author declares there are no conflicts of interest.

\section{Funding}

None.

\section{References}

1. El-Guindy A. Endoscopic transseptal sphenopalatine artery ligation for intractable posterior epistaxis. Ann OtolRhinol Laryngol. 1998;107(12):1033-1037.

2. Thornton MA, Mahesh BN, Lang J . Posterior Epistaxis: Identification of Common Bleeding Sites. Laryngoscope. 2005; 115(4):588-590.

3. Pahor AL. Pharaonicotorhinolaryngology. International congress series. 2003;1240:1349-1359.

4. Pope L, Hobbs C. Epistaxis: an update on current management. Postgrad Med J. 2005;81(955): 309-314.

5. Pringle MB, Beasley P, Brightwell AP. The use of Merocel nasal packs in the treatment of epistaxis. J Laryngol Otol. 1996;110(6):543-546.

6. Holland NJ, Sandhu GS, Ghufoor K, et al. The Foley catheter in the management of epistaxis. Int J ClinPract. 2010;55(1):14-15.
7. Rotenberg B, Tam S. Respiratory complications from nasal packing: systematic review. J Otolaryngol Head Neck Surg. 2010;39(5):606-614.

8. Bartlett W, McKittrick OF. A Study Of Secondary Hemorrhage Treated By Ligation Of The Common Carotid Artery. Ann Surg. 1917;65(6):715-729.

9. Seiffert A. Unterbinding der arteria maxillaris interna. Z Hals Nasen Ohrenh. 1928;22:323-325.

10. Winstead W. Sphenopalatine artery ligation: An alternative to Internal Maxillary artery ligation for intractable posterior epistaxis. Laryngoscope. 1996;106(5):667-669.

11. Breda S, Choi IS, Perskey MS, et al. Embolisation in the treatment of epistaxis after failure of internal maxillary artery ligation. Laryngoscope. 1989;99(8):809-813.

12. Lee HY, Kim HU, Kim SS, et al. Surgical anatomy of the sphenopalatine artery in lateral nasal wall. Laryngoscope. 2002;112(10):1813-1818.

13. Feusi B, Holzmann D, Steurer J. Posterior epistaxis: systematic review on the effectiveness of surgical therapies. Rhinology. 2005;43(4):300-304.

14. Budrovich R, and Saetti R. Microscopic and endoscopic ligature of the sphenopalatineartery. Laryngoscope. 1992;102(12):1390-1394.

15. Evans D. Overview of Methods, in Reviewing Research Evidence for Nursing Practice: Systematic Reviews .In: Webb C and Roe B (Eds.), Blackwell Publishing Ltd, Oxford, UK. 2007.

16. Sackett DL, Rosenberg WM, Gray JA, et al. Evidence based medicine: what it is and what it isn't. BMJ. 1996;312(7023):71-72.

17. Higgins JPT, Green S. Cochrane Handbook for Systematic Reviews of Interventions Version 5.0.2. The Cochrane Collaboration John Wiley \& Sons, Ltd, UK. 2009.

18. McGarry GW. Nasal endoscope in posterior epistaxis: a preliminary evaluation. J Laryngol Otol. 1991;105(6):428-431.

19. Moshaver A, Harris JR, Liu R, et al. Early operative intervention versus conventional treatment in epistaxis: randomized prospective trial. $J$ Otolaryngol. 2004;33(3):185-188.

20. Vergara Hernández J, Ordóñez LE. Surgical versus non-surgical treatment of posterior Epistaxis. Acta Otorrinolaringol Esp. 2006;57(1):41-46.

21. Klotz DA, Winkle MR, Richmon J, et al. Surgical management of posterior epistaxis: a changing paradigm. Laryngoscope. 2002;112(9):1577-1582.

22. Ha JF, Hodge JC, Lewis R. Comparison of nasendoscopic-assisted cautery versus packing for the treatment of epistaxis. ANZ J Surg. 2011;81(5):336-339.

23. Schaitkin B, Strauss M, Houck JR. Epistaxis: Medical versus surgical therapy: a comparison of efficacy, complications, andeconomic considerations. Laryngoscope. 1987;97(12):1392-1395.

24. Kumar S, Shetty A, Rockey J, et al. Contemporary surgical treatment of epistaxis. What is the evidence for sphenopalatine artery ligation? Clin Otolaryngol Allied Sci. 2003; 28(4):360-363. 